\title{
EVALUATION OF OUTCOMES OF ENHANCED RECOVERY AFTER SURGERY PROGRAMME IN SLEEVE GASTRECTOMY
}

By

\author{
Ahmed Mohammed Abd El-Ghany Shrery, Ahmed Shwky Abd El-Azez \\ and Walid Raafat Abd El-Atey
}

Department of General Surgery, Faculty of Medicine, Al-Azhar University

Corresponding author: Ahmed Mohammed Abd El-Ghany Shrery,

E-mail: ahmed_shrery852@gmail.com

\begin{abstract}
Background: Strategic multidisciplinary protocols for enhanced recovery after surgery (ERAS) have demonstrated reductions in length of hospital stay (LOS), morbidity, and costs in conjunction with bariatric procedures, Although enhanced recovery after surgery has made great progress in the field of surgery, the guidelines point to the lack of high-quality evidence in upper gastrointestinal surgery.
\end{abstract}

Objectives: To evaluate the outcomes of ERAS program in sleeve gastrectomy.

Patients and methods: This was a randomized clinical trial that was carried out at Al-Hussein Hospital, AlAzhar University. The study was conducted on 50 patients. All patients underwent sleeve gastrectomy during the study period. The patients in the group A received conventional perioperative care plan, and ERAS perioperative care plan was given to the patients in the group B.

Results: There was a significant difference between the two studied groups regarding complications which were more frequent in group A. There was a significant difference between the two studied groups regarding early oral intake, drain from components compliance, and overall compliance.

Conclusion: The enhanced recovery after surgery protocol in the setting of bariatric surgery shortened hospital stay and was cost-effective. There was no increase in perioperative morbidity. Enhanced recovery after surgery was safe, effective in laparoscopic bariatric surgery, and can be further clinically popularized.

Keywords: Bariatric surgery, Laparoscopic, Enhanced recovery, ERAS, compliance, conventional, complications, morbidity.

\section{INTRODUCTION}

Enhanced recovery after surgery (ERAS) programs have been very important to surgeons who are keen to decrease postoperative morbidity, reducing variability in postoperative care and minimizing hospital costs. The delay in full recovery after major surgery has been improved significantly by introducing a series of modifications throughout the whole perioperative period and summarizing these modifications in a program called the enhanced recovery after surgery (ERAS) program (Gustafsson et al., 2013).

Significant improvements in outcomes subsequent to abdominal major operations can be accomplished by implementing a consistent protocol on evidence-based medicine in all perioperative steps (Teeuwen et al., 2011). 
This method has merged into enhanced recovery after surgery (ERAS) pathway, which has progressed into a wider model named the perioperative surgical home. Enhanced recovery after surgery (ERAS) pathways involves a series of perioperative evidence-based interventions that were developed initially for elective colorectal surgery. ERAS pathways aim to maintain physiological function, enhance mobilization, reduce pain and facilitate early oral nutrition postoperatively by reducing perioperative surgical stress. The adoption of ERAS pathways has resulted in improved outcome in terms of reduced morbidity, faster recovery and reduced length of hospital stay in dedicated centres (Thorell et al., 2016).

There is an association between ERAS and improved postoperative short-term outcomes, comprising decline in length of hospital stay, decrease in morbidity, quicker resume of bowel function, faster ambulation, and lower pain scores (Eskicioglu et al., 2010).

Laparoscopic sleeve gastrectomy is the most commonly performed bariatric surgery in the world. Enhanced recovery after surgery (ERAS) protocols has been shown to reduce complications and decrease length of stay for various types of surgeries. A cost-effective ERAS protocol for laparoscopic sleeve gastrectomy results in shorter length of stay, without increase in perioperative morbidity or readmission rates (Lam et al., 2019).

ERAS is widely used in general surgery, cardiac surgery, obstetrics, gynecology, and other multidisciplinary fields. Being overweight has become a global epidemic, surgical treatment is an important tool for long-term and stable weight loss in severely obese patients (Kalogera and Dowdy, 2019).

Laparoscopic bariatric surgery has extensively acquired development due to its minimal invasion, low incidence of postoperative complications, and significant curative effects. It is commonly used in treatment of obesity and metabolic disease (Barreca et al., 2016).

ERAS refers to the complete process of smooth and rapid recovery of patients during perioperative period. It cannot simply be interpreted as fast surgery. In ERAS, detailed perioperative period diagnosis and treatment strategies are required to reduce the body stress reaction, especially the negative effects (Sammour et al., 2010).

The aim of the present study was to evaluate the outcomes of ERAS program in sleeve gastrectomy.

\section{PATIENTS AND METHODS}

This was a randomized clinical trial that carried out at Al-Hussein Hospital, Al-Azhar University. The study was conducted on 50 patients; all patients were undergoing to do sleeve gastrectomy during the study period, the patients in the group A received conventional perioperative care plan, and ERAS perioperative care plan was applied to the patients in the group B.

Inclusion criteria: Both males and female, age: between 18 to 60 years, and BMI above 40 .

Exclusion criteria: Risky chronic disease, hepatic, cardiac and renal 
patients. Patients were randomized into two groups:

The patients in group A received conventional perioperative care plan, and ERAS perioperative care plan was given to the patients in the group B. The patients have verbal and written information regarding ERAS protocol and a signed consent was obtained further.

The patient had first following up visit 7 to 10 days after surgery. Bariatric enhanced recovery after surgery protocol compared with standard care

All staff and nurses were educated about the ERAS care strategy. The preoperative preparation procedure did not comprise mechanical bowel preparation. Patients received $200 \mathrm{ml}$ of carbohydraterich drinks four times a day before the surgery, and two doses on the morning of the operation. Patients were kept fasting before the operation: $2 \mathrm{~h}$ for liquids and 6 $\mathrm{h}$ for solids. Prophylactic IV antibiotic (metronidazole 500mg) and (ceftriaxone 1 g)was given $1 \mathrm{~h}$ before surgery and sustained for $24 \mathrm{~h}$ subsequently (two extra doses). Prophylactic therapy was given against thromboembolism: subcutaneous enoxaparin $40 \mathrm{mg}$ given $12 \mathrm{~h}$ before insertion of epidural catheter and sustained as 40mg once daily until discharge. Starting at midnight before the surgery, patients did not take any medications recognized to cause longterm sedation. Short-acting drugs only were allowed to aid in insertion of epidural catheter.

\section{Statistical Analysis:}

Data entry, processing and statistical analysis was carried out using using SPSS version 20 (Statistical Package for the Social Sciences).

$$
\mathrm{P} \leq 0.05 \text { was considered significant. }
$$

\section{Descriptive statistics:}

Mean, Standard deviation ( \pm SD). Frequency and percentage of nonnumerical data. T-test was used to compare quantitative data, and Chi2 was usedto compare qualitative data . Hospital stay and pain score was calculated using Mann-_Whitney U test. 
AHMED M. A. SHRERY et al.,

\section{RESULTS}

No significant difference between the groups as regards age, sex, weight, height and BMI (Table 1).

Table (1): Demographic data of the two studied groups

\begin{tabular}{|l|l|c|c|c|}
\hline \multicolumn{1}{|c|}{ Groups } & \multicolumn{1}{|c|}{$\begin{array}{c}\text { Group A } \\
\text { Parameters }\end{array}$} & $\begin{array}{c}\text { Group B } \\
(\mathbf{n = 2 5})\end{array}$ & P \\
\hline $\begin{array}{l}\text { Age(years) } \\
\text { Mean } \pm \text { SD }\end{array}$ & $37.15 \pm 4.29$ & $38.4 \pm 3.76$ & $>0.05$ \\
\hline \multirow{2}{*}{ Sex } & Male & $5(20 \%)$ & $3(12 \%)$ & $>0.05$ \\
\cline { 2 - 5 } & Female & $20(80 \%)$ & $22(88 \%)$ & $>0.05$ \\
\hline $\begin{array}{l}\text { Weight }(\mathrm{kg}) \\
\text { Mean } \pm \text { SD }\end{array}$ & $152.84 \pm 21.59$ & $162.4 \pm 19.86$ & $>0.05$ \\
\hline $\begin{array}{l}\text { Height }(\mathrm{cm}) \\
\text { Mean } \pm \text { SD }\end{array}$ & $167.56 \pm 6.89$ & $168.44 \pm 7.37$ & $>0.05$ \\
\hline $\begin{array}{l}\text { BMI }\left(\mathrm{kg} / \mathrm{m}^{2}\right) \\
\text { Mean } \pm \text { SD }\end{array}$ & $54.68 \pm 8.77$ & $57.28 \pm 9.83$ & \\
\hline
\end{tabular}

There was no significant difference between the two studied groups regarding hypertension, diabetes, smoking and hypercholesterolemia. There was a significant difference between the two studied groups as regard hospital stay. No significant difference between the two groups as regards pain score. There was a significant difference between the two studied groups regards early oral intake and drain from components compliance, nausea vomiting and early pass flutes/stool, and regarding overall compliance. There was a significant difference between the two studied groups regarding complications which were more frequent in group $\mathrm{A}$. There was a significant difference between the two groups regarding early discharge. No significant difference between the two groups regarding readmission causes and 1st week follow (Table 2). 
Table (2): Co-morbidities, hospital stay distribution, compliance with components of the enhanced recovery after surgery, complications, discharge and readmission, readmission causes and follow up between the two studied groups

\begin{tabular}{|c|c|c|c|c|c|}
\hline \multicolumn{3}{|c|}{$\begin{array}{l}\text { Groups } \\
\text { Parameters }\end{array}$} & $\begin{array}{c}\text { Group A } \\
(\mathbf{n}=25)\end{array}$ & $\begin{array}{l}\text { Group B } \\
(\mathbf{n}=25)\end{array}$ & $\mathbf{P}$ \\
\hline \multirow{4}{*}{$\begin{array}{l}\text { Co- } \\
\text { morbidities }\end{array}$} & \multicolumn{2}{|c|}{ Hypertension } & $6(24 \%)$ & $3(12 \%)$ & $>0.05$ \\
\hline & \multicolumn{2}{|l|}{$\mathrm{DM}$} & $4(16 \%)$ & $3(12 \%)$ & $>0.05$ \\
\hline & \multicolumn{2}{|c|}{ Hypercholesterolemia } & $18(72 \%)$ & $15(60 \%)$ & $>0.05$ \\
\hline & \multicolumn{2}{|c|}{ Smoking } & $9(36 \%)$ & $7(28 \%)$ & $>0.05$ \\
\hline $\begin{array}{l}\text { Hospital stay } \\
\text { (days) }\end{array}$ & \multicolumn{2}{|c|}{ Mean \pm SD } & $2.72 \pm 0.798$ & $2.32 \pm 0.684$ & $>0.05$ \\
\hline Pain score & \multicolumn{2}{|c|}{ Mean \pm SD } & $3.46 \pm 0.86$ & $3.13 \pm 0.94$ & $>0.05$ \\
\hline \multirow{8}{*}{$\begin{array}{l}\text { Compliance } \\
\text { with } \\
\text { components of } \\
\text { the enhanced } \\
\text { recovery after } \\
\text { surgery }\end{array}$} & \multicolumn{2}{|c|}{ Early mobilization } & $3(12 \%)$ & $6(24 \%)$ & $>0.05$ \\
\hline & \multicolumn{2}{|l|}{ Nausea } & $11(44 \%)$ & $7(28 \%)$ & $>0.05$ \\
\hline & \multicolumn{2}{|c|}{ Vomiting } & $13(52 \%)$ & $8(32 \%)$ & $>0.05$ \\
\hline & \multicolumn{2}{|c|}{ Early pass flutes/stool } & $7(28 \%)$ & $12(48 \%)$ & $>0.05$ \\
\hline & \multicolumn{2}{|c|}{ Early Oral intake } & $3(12 \%)$ & $9(36 \%)$ & 0.047 \\
\hline & \multicolumn{2}{|l|}{ Drain } & $5(20 \%)$ & 0 & 0.018 \\
\hline & \multicolumn{2}{|c|}{ Catheter output } & $2(8 \%)$ & 0 & 0.149 \\
\hline & \multicolumn{2}{|c|}{ Overall compliance } & $8(32 \%)$ & $17(72 \%)$ & 0.011 \\
\hline \multirow{3}{*}{ Complications } & \multicolumn{2}{|c|}{ No } & $17(68 \%)$ & $24(96 \%)$ & \\
\hline & \multicolumn{2}{|c|}{ Wound related } & $4(16 \%)$ & $1(4 \%)$ & $\mathbf{0 . 0 3 0}$ \\
\hline & \multicolumn{2}{|c|}{ Systemic related } & $4(16 \%)$ & 0 & \\
\hline \multirow{2}{*}{$\begin{array}{l}\text { Discharge and } \\
\text { readmission }\end{array}$} & \multicolumn{2}{|c|}{ Early Discharge } & $13(52 \%)$ & $20(80 \%)$ & 0.037 \\
\hline & \multicolumn{2}{|c|}{ Readmission } & $8(32 \%)$ & $3(12 \%)$ & 0.088 \\
\hline \multirow{4}{*}{$\begin{array}{l}\text { Readmission } \\
\text { causes }\end{array}$} & \multicolumn{2}{|c|}{ Epigastric pain } & $3(12 \%)$ & $2(8 \%)$ & \multirow{4}{*}{0.662} \\
\hline & \multicolumn{2}{|c|}{ Vomiting } & $2(8 \%)$ & 0 & \\
\hline & Postoper & ve ileus & $2(8 \%)$ & $1(4 \%)$ & \\
\hline & \multicolumn{2}{|c|}{ Postoperative leak } & $1(4 \%)$ & 0 & \\
\hline \multirow{4}{*}{ Follow up } & \multirow{3}{*}{$1^{\text {st }}$ week } & Very good & $5(20 \%)$ & $20(80 \%)$ & \multirow{3}{*}{0.001} \\
\hline & & Good & $19(76 \%)$ & $5(20 \%)$ & \\
\hline & & Poor & $1(4 \%)$ & 0 & \\
\hline & $2^{\text {nd }}$ week & & $148.52 \pm 19.46$ & $152.76 \pm 17.47$ & 0.422 \\
\hline
\end{tabular}

There was a significant reduction in both groups. Moreover, group B was more significant compared to group A (Table 3).

Table (3): Change in weight between the two studied groups

\begin{tabular}{|l|c|c|c|}
\hline Groups Paired Differences & Mean \pm SD & $\begin{array}{c}\text { 95\% Confidence Interval } \\
\text { of the Difference }\end{array}$ & P value \\
\hline Group A & $\mathbf{8 . 6 4} \pm \mathbf{5 . 6 1}$ & $\mathbf{6 . 3 2 7}-\mathbf{1 0 . 9 5 3}$ & $\mathbf{0 . 0 0 1}$ \\
\hline Group B & $\mathbf{4 . 3 2} \pm \mathbf{0 . 9 0 0}$ & $\mathbf{3 . 9 4 8}-\mathbf{4 . 6 9 2}$ & $\mathbf{0 . 0 0 1}$ \\
\hline
\end{tabular}

\section{DISCUSSION}

Analysis of our results revealed nonstatistical significant difference between the two studied groups regarding age, sex, weight, height and BMI. Awad et al. (2013) and Blanchet et al. (2017). Li and Fang (2018) revealed the same results. 
As regards co-morbidities, the present study reported that there was no statistical significant difference between the two studied groups regarding hypertension, diabetes, smoking and hypercholesterolemia. Awad et al. (2013), reported that hypertension, diabetes mellitus, sleep apnea and limited mobility were present in $40 \%, 34 \%, 24 \%$ and $9 \%$ of patients, respectively. Blanchet et al. (2017) found that more than 50\% presented with multiple comorbidities, including $70.1 \%$ with articular disease, $17.4 \% \quad$ hypertension, $\quad 15.2 \%$ hyperlipidemia, $11.5 \%$ obstructive sleep apnea (OSA), and $6.7 \%$ with type 2 diabetes mellitus (T2DM).

Bariatric surgery is the most successful treatment for obesity; yet, the perception that it is accompanied by a challenging postoperative course and complicated rehabilitation is a barrier to its greater acceptance by patients and referring physicians (Wharton et al., 2016).

$L i$ and Fang (2018) demonstrated that the hospital stay length in ERAS group was significantly shorter than in the control group and hospitalization cost in ERAS group was significantly less than that in the control group.

Furthermore, the clinical trial of Lemanu et al. (2013) reported that patients having LSG within an ERAS protocol had a significant reduction in postoperative length of hospital stay compared with those not treated within this protocol. The reduction in hospital stay did not come at the expense of increased postoperative morbidity. The length of stay was still significantly shorter than that in a historical group, which was used to account for potential crossover between the study groups. This study was unable to quantify the effect of the individual components of the ERAS protocol on this reduction in hospital stay.

As regard postoperative pain score, the present study revealed no significant difference between the two groups. In agreement with our findings, the study of $\mathrm{Li}$ and Fang (2018) reported that there was significant difference between the two groups.

As regards compliance with components of the enhanced recovery after surgery between the two studied groups, There was a significant difference between the two studied groups regarding early oral intake and drain from components compliance and regarding overall compliance.

Even though a meta-analysis of observational studies of postoperative complication outcome was done by Siotos et al. (2018), it did not give a detailed list that classified the complications. A metaanalysis of Wang et al. (2018) indicated that the ERAS protocol increased the rate of readmissions in elderly patients with gastric cancer, but this result requires more studies to confirm its findings, it is only for the analysis of Gastrectomy.

In the present study, there was a significant difference between the two studied groups regarding complications which were more frequent in group A. In a systemic analysis of Huang et al. (2020), reported that among RCTs performed in the area of gastric surgery, analysis indicated that the incidence of SSI after surgery was not increased by ERAS protocols. Among RCTs performed in the area of esophagectomiesy surgery, the incidence of SSI was not increased. 
However, there were no statistical differences in all subgroup analyses of SSI based on the surgical procedure and scope of gastrectomy. The results suggested that ERAS protocols did not increase the incidence of postoperative anastomotic leakage compared to conventional care $(\mathrm{RR}=0.80,95 \% \mathrm{CI}: 0.44$ to 1.45$)$.

The current study revealed that there was a significant difference between the two groups regarding early discharge, while there was non- statistical significant difference between groups as regard readmission. Huang et al. (2020) reported postoperative readmission rates. No increase in postoperative readmission rates compared to conventional care), meanwhile; among RCTs performed in the area of gastric surgery, analysis indicated readmission was significantly increased by ERAS protocols. Among RCTs performed in the area of esophagectomies, readmission rates did not increase by ERAS protocol.

Furthermore, the current study demonstrated that there was no significant difference between the two studied groups as regard 1 st week follow.

Li and Fang (2018) demonstrated that satisfaction rate in ERAS group was significantly higher than that in the control group.

Blanchet et al. (2017) reported in their study that after 1 month, there was $92.5 \%$ follow-up, failed to attend the first postoperative consultation. Overall patient satisfaction was high (99.0\%) and reported that they were satisfied with this clinical pathway, and they would recommend it to others.
As regards weight reduction, the present study revealed that there was a significant weight reduction in both groups, Moreover, group B was more significant compared to group A.

One of the main limitations of this study was the lack of blinding and subsequent risk of performance bias. This limitation has been encountered in all previous randomized trials investigating ERAS (Spanjersberg et al., 2011). Blinding seems unavoidable with ERAS because patients and staff must be made aware of what is expected of them in order to meet their outcome goals. Although useful in generating hypotheses, purely observational studies evaluating ERAS are limited in their ability to make sound conclusions owing to the inability to account accurately for known confounders. Future studies investigating the efficacy of ERAS interventions may choose to use this method to avoid the inevitable bias associated with nonblinding in randomized trials evaluating ERAS protocols.

\section{CONCLUSION}

ERAS programs were associated with a significant reduction in postoperative LI, meanwhile ERAS protocols accelerated patients' postoperative recovery times, performance ERAS may decrease the risk of postoperative ileus or readmission rate. ERAS is evolving and not yet standardized for bariatric surgery. ERAS programs that result in outcomes comparable to or better than traditional care reduce LOS, morbidity, and costs.

\section{REFERENCES}

1. Awad EO, Tubio DL, Navarro FL, Carvajal FM, Adan NG, Bautista MR and Osinaga JA (2013): Enhanced Recovery After Bariatric 
Surgery (ERABS): Clinical Outcomes from a Tertiary Referral Bariatric Centre. Obesity Surgery, 24: 36-42.

2. Barreca M, Renzi C, Tankel J, Shalhoub J and Sengupta $N$ (2016): Is there a role for enhanced recovery after laparoscopic bariatric surgery? Preliminary results from a specialist obesity treatment center. Surg Obes Relat Dis., 12: $119-126$.

3. Blanchet M, Benoît G, Yann M, Alexandre V, Thomas L, Fabienne $M$ and Vincent $F$ (2017): Experience with an Enhanced Recovery After Surgery (ERAS) Program for Bariatric Surgery: Comparison of MGB and LSG in 374 Patients. Obes Surg., 27:18961900.

4. Eskicioglu C, Forbes SS, Aarts MA, Okrainec A, McLeod RS (2010): Enhanced recovery after surgery (ERAS) programs for patients having colorectal surgery: a metaanalysis of randomized trials. Journal of Gastrointestinal Surgery, 13(12):2321-2325.

5. Gustafsson UO, Scott MJ, Schwenk W, Demartines $\mathbf{N}$, Roulin $\mathbf{D}$, Francis $\mathbf{N}$, McNaught CE, Macfie J, Liberman AS, Soop $M$ and Hill A (2013): Guidelines for perioperative care in elective colonic surgery: Enhanced Recovery After Surgery (ERAS®) Society recommendations. World Journal of Surgery, 37(2):259-84.

6. Huang ZD, Gu HY, Zhu J, Luo J, Shen XF, Deng QF, Zhang C and Li YB (2020): The application of enhanced recovery after surgery for upper gastrointestinal surgery: Metaanalysis. BMC Surgery, 20(1):3-9.

7. Kalogera E and Dowdy SC (2019): Enhanced Recovery After Surgery and Acute Postoperative Pain Management. Clinical Obstetrics and Gynecology, 62(4): 656-665.

8. Lam J, Suzuki T, Bernstein D, Zhao B, Maeda C, Pham T, Sandler BJ, Jacobsen GR, Cheverie JN and Horgan S (2019): An ERAS protocol for bariatric surgery: is it safe to discharge on post-operative day 1 ? Surgical Endoscopy, 33(2):580-6.

9. Lemanu DP, Singh PP, Berridge K, Burr M, Birch C, Babor R, MacCormick AD, Arroll $B$ and Hill AG (2013): Randomized clinical trial of enhanced recovery versus standard care after laparoscopic sleeve gastrectomy. British Journal of Surgery, 100(4):482-9.

10. Li Y and Fang D (2018): Efficacy and safety of enhanced recovery after surgery for patients undergoing laparoscopic bariatric surgery. Int J Clin. Exp Med., 11(6):6180-6186.

11.Sammour T, Zargar-Shoshtari K, Bhat A, Kahokehr A and Hill AG (2010): A programme of enhanced recovery after surgery (ERAS) is a cost-effective intervention in elective colonic surgery. N Z Med J., 123: 6170.

12. Siotos C, Stergios K, Naska A, Frountzas M, Pergialiotis V and Perrea DN. (2018): The impact of fast track protocols in upper gastrointestinal surgery: a meta-analysis of observational studies. Surgeon, 16:183-92.

13.Spanjersberg WR, Reurings J, Keus F and van Laarhoven CJ (2011): Fast track surgery versus conventional recovery strategies for colorectal surgery. Cochrane Database Syst Rev., 2: 7635-42.

14. Teeuwen PH, Bleichrodt RP, de Jong PJ, van Goor $H$ and Bremers AJ (2011): Enhanced recovery after surgery versus conventional perioperative care in rectal surgery. Diseases of the Colon \& Rectum, 54(7):833-9.

15. Thorell A, MacCormick AD, Awad S, Reynolds N, Roulin D, Demartines N, Vignaud M, Alvarez A, Singh PM and Lobo DN (2016): Guidelines for perioperative care in bariatric surgery: enhanced recovery after surgery (ERAS) society recommendations. World Journal of Surgery, 40(9):2065-83.

16. Wang LH, Zhu RF, Gao C, Wang SL and Shen LZ (2018): Application of enhanced recovery after gastric cancer surgery: an updated meta-analysis. World J Gastroenterol., 24:1562-78. 


\section{EVALUATION OF OUTCOMES OF ENHANCED RECOVERY AFTER... 2617}

\section{تقييم المحصلة لبرنامج التعافي المحسن بعد الجر احة في تكميم

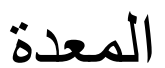

أحمد محمد عبد الغني، احمد شوقي عبد العزيز، وليد رأفت عبد العاطي

قسم الجراحة العامة، كلية الطب، جامعة الأزهر

E-mail: ahmed_shrery852@gmail.com

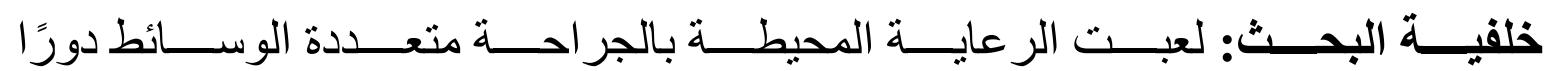

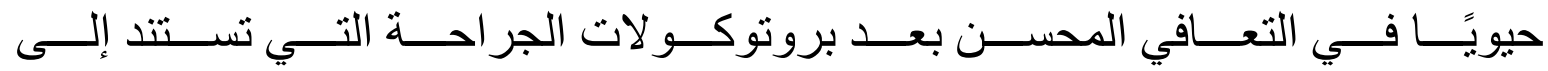

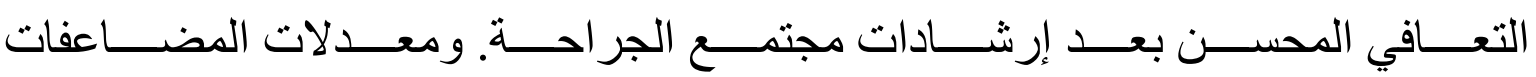

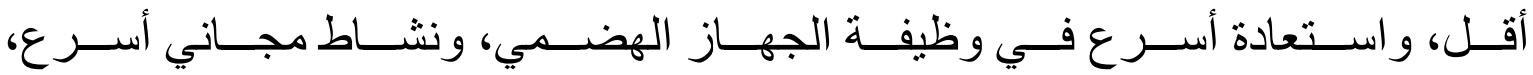

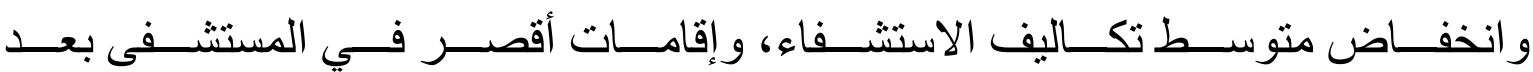
الجراحة في المرضى في مجموعة التعافي المحسن بعد الجراحة.

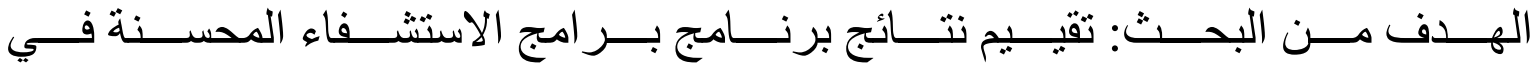
البداية في جر احة تكميم المعدة.

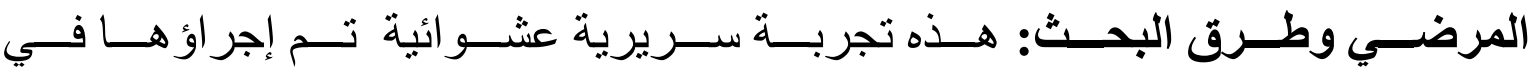

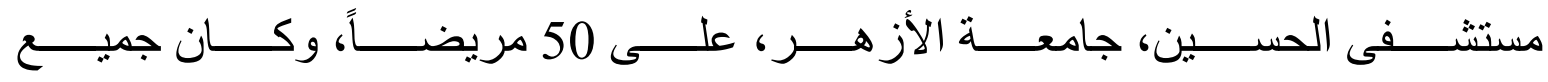

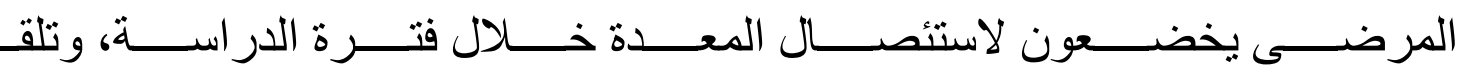

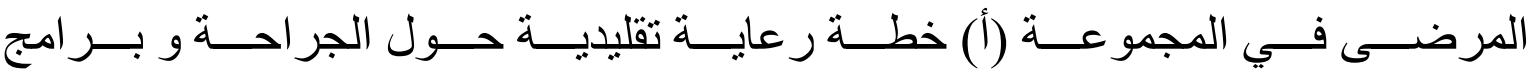

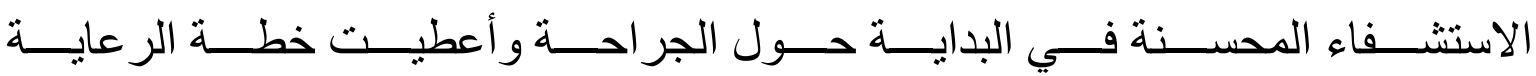
للمرضى في المجمو عة (ب).

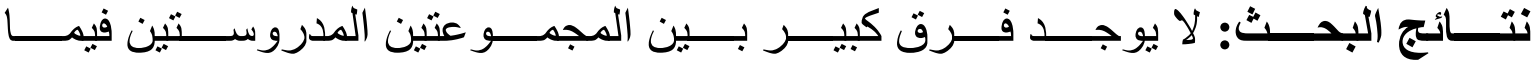

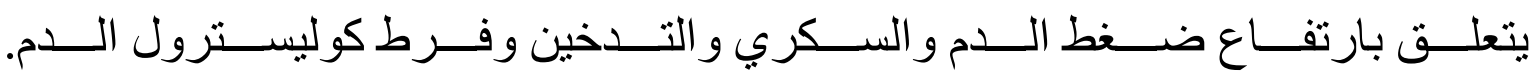

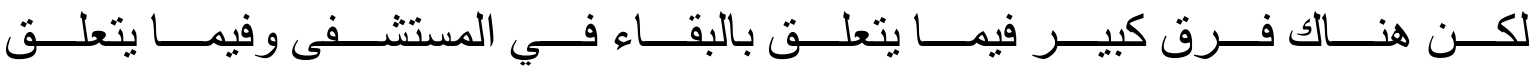

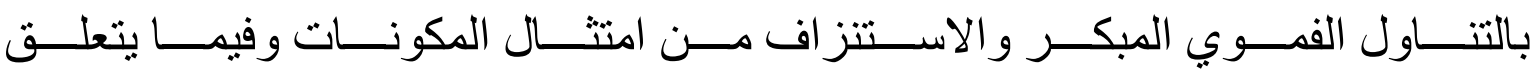




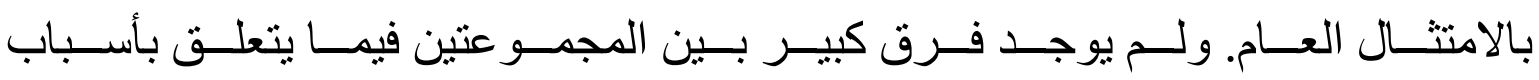

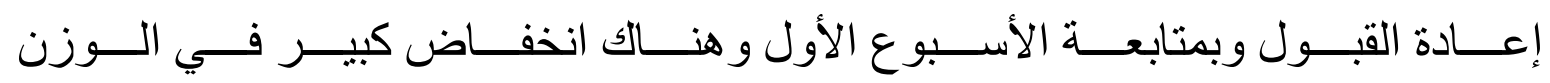
في كلا المجمو عتين.

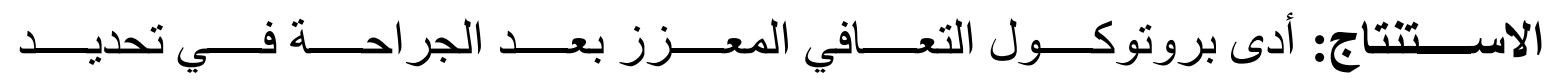

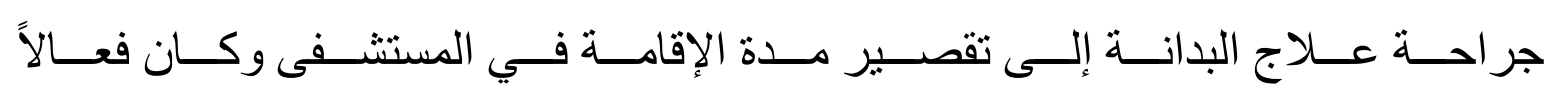

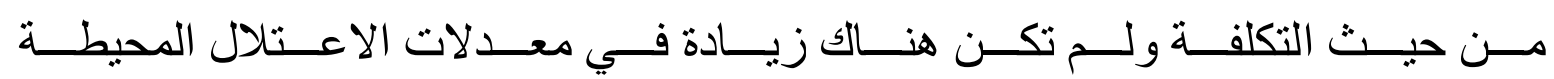

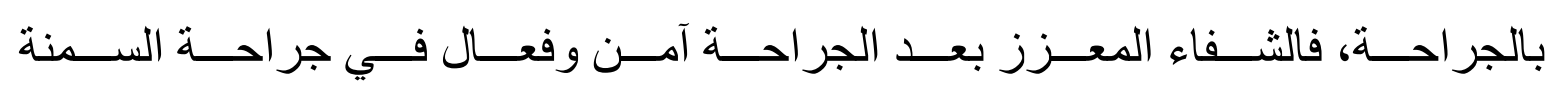
بالمنظار ويمكن زيادة إنتشاره سريريًا.

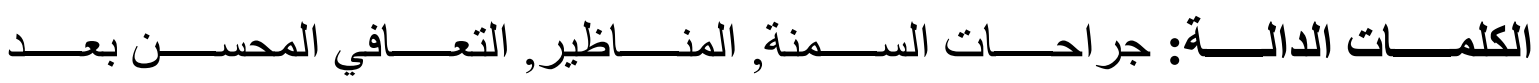
الجر احة, الامتثال العام, المخاطر, المضاعفات. 